Revista Universo Contábil, ISSN 1809-3337

FURB, v. 5, n.4, p. 63-75, out./dez., 2009

doi:10.4270/ruc.2009431

Disponível em www.furb.br/universocontabil

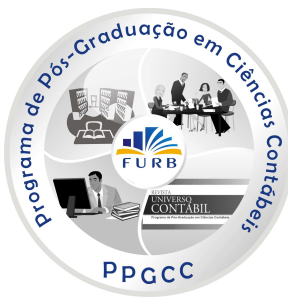

\title{
CONSIDERAÇÕES SOBRE AS FUNÇÕES DA CONTROLADORIA NOS ESTADOS UNIDOS, ALEMANHA E BRASIL*
}

\section{THE CONTROLLERSHIP FUNCTIONS IN THE UNITED STATES, GERMANY AND BRAZIL}

Rogério João Lunkes

Doutor em Engenharia de Produção pela EPS/UFSC

Professor da Universidade Federal de Santa Catarina Endereço: Rua Acelon P. da Costa, 231, B1. C, Apto. 401, Itacorubi CEP: 88034-040 - Florianópolis/SC - Brasil E-mail: rogeriolunkes@ hotmail.com Fone: (48) 3721-6634

Darci Schnorrenberger

Doutor em Engenharia de Produção pela EPS/UFSC

Professor da Universidade Federal de Santa Catarina Endereço: Centro Sócio-Econômico - Campus Universitário - Trindade CEP: 88040-970 - Florianópolis/SC - Brasil E-mail: darcisc@gmail.com Fone: (48) 3721-6634

Valdirene Gasparetto

Doutora em Engenharia de Produção pela EPS/UFSC

Professor da Universidade Federal de Santa Catarina Endereço: Centro Sócio-Econômico - Campus Universitário - Trindade CEP: 88040-970 - Florianópolis/SC - Brasil

E-mail: valdirene@cse.ufsc.br Fone: (48) 3721-6634

\section{Ernesto Fernando Rodrigues Vicente}

Doutor em Administração pela FEA/USP

Professor da Universidade Federal de Santa Catarina Endereço: Centro Sócio-Econômico - Campus Universitário - Trindade CEP: 88040-970 - Florianópolis/SC - Brasil

E-mail: e.fernando@cse.ufsc.br Fone: (48) 3721-6634

Artigo recebido em 29.10.2008. Revisado por pares em 19.02.2009. Reformulado em 26.03.2009. Recomendado em 31.03.2009 por Ilse Maria Beuren (Editora). Publicado em 30.11.2009. Organização responsável pelo periódico: FURB. 


\section{RESUMO}

A definição de um conjunto de funções é um dos pontos fundamentais em qualquer estudo de controladoria. Entretanto, o leitor tem encontrado dificuldades neste aspecto em decorrência de definições e concepções insatisfatórias, confusas e muitas vezes contraditórias, na literatura. Diante disso, este trabalho tem como objetivo identificar um conjunto de funções da controladoria em manuais e obras de referência nos Estados Unidos, Alemanha e Brasil. Quanto ao delineamento, o trabalho conforma-se como descritivo, sendo conduzido através de levantamento bibliográfico. Os resultados mostram que as funções mais citadas são as de planejamento, com $87 \%$, e controle, com $83 \%$, demonstrando que o papel do controller possui um caráter proativo na organização. Evidencia também que a controladoria, no seu desenvolvimento, tem incorporado funções mais amplas e sistêmicas.

Palavras-chave: Controladoria. Funções. Planejamento. Controller.

\section{ABSTRACT}

The definition of a set of functions is one of the most fundamental issues in any controllership study. However, readers have faced difficulties in this aspect because of unsatisfactory concepts, sometimes confusing and many times controversial, found in specialized literature. Thus, the goal of the present work is to identify a set of controllership functions found in the research published on the subject in the United States, Germany and Brazil. A descriptive work was done through a bibliographical data. The results show that the most quoted functions are planning, with $87 \%$, and controlling, with $83 \%$, in a clear indication that the controller has a pro-active character in organizations. It also shows that the controllership, in its development, has incorporated wider and systemic functions.

Keywords: Controllership. Functions. Planning. Controller.

\section{INTRODUÇÃO}

As organizações contemporâneas têm experimentado pressões competitivas sem precedentes, sendo assim forçadas a criar continuadamente mecanismos para diferenciar-se e incrementar seus níveis de competitividade. Neste contexto, há dois pontos interdependentes já apontados nos trabalhos de Ansoff (1975), que têm aumentado significativamente de complexidade nas últimas décadas. O primeiro diz respeito à dinâmica e complexidade do ambiente empresarial, que é caracterizado pela freqüência e velocidade das mudanças dos diferentes segmentos do ambiente e pela sua força, regularidade e previsibilidade. O segundo, aparece como resposta ao primeiro e está relacionado a diferenciação. Isto ganha força nos mais diferentes arranjos empresariais, e se manifesta na massiva setorização da estrutura organizacional e nas relações com o ambiente, no difuso sistema de gestão e também nas estruturas de poder que determinam as direções da organização.

Frente a este quadro, onde o velho não mais atende plenamente e o novo ainda não é dominado totalmente, para manterem-se competitivas as organizações têm demandado, cada vez mais, melhorias em seus processos e controles. Neste contexto, a controladoria passa a exercer um papel central no processo de gestão. Seu desenvolvimento ocorreu a partir dos preceitos básicos da contabilidade para uma ampla função de suporte informacional, controle interno, planejamento tributário, elaboração do orçamento e medidas operacionais, passando a participar também ativamente da formulação das estratégias, fazendo com que deixasse de ser apenas um compilador de dados e passasse a ser um gestor da informação, responsável pelo planejamento estratégico das organizações. 
Neste sentido, Roehl-Anderson e Bragg (1996) defendem que o controller, mais que o responsável pela contabilidade, é um executivo da empresa que frequentemente deve orientar na direção, controle e proteção do negócio. Defendem ainda que o controller não é o comandante do navio, tarefa que compete ao executivo principal (CEO), mas pode ser comparado ao navegador, que mantém controle sobre os instrumentos de navegação. Deve manter o comandante informado sobre a distância navegada, a velocidade imprimida, resistências encontradas, variações de curso, recifes perigosos à frente e onde as tábuas de navegação indicam que o CEO deve encontrar e alcançar o próximo porto em segurança.

Nesta linha, Siegel e Kulesza (1996, p. 22) asseveram que a controladoria tem se especializado no apoio à decisão. Tem a função de garimpar a informação, transformando-a de tal forma que auxilie e facilite a tomada de decisão das demais áreas. Anthony e Govindarajan (2001) entendem que a controladoria desempenha um importante papel na preparação de planos estratégicos e orçamentários. Atkinson et al. (2000) e Garrison e Noreen (2001, p.17) defendem que no atual contexto a controladoria está se tornando parte da alta administração, participando da formulação e da implementação de estratégias, cabendo-lhe a tarefa de traduzir o plano estratégico em medidas operacionais e administrativas.

Autores como Jackson (1949), Heckert e Willson (1963), Tung (1974), Yoshitake (1984), Brito (2005) e Padoveze e Benedicto (2005) apresentam a contabilidade como uma das funções básicas da controladoria. Autores como Almeida, Parisi e Pereira (2001), Peleias (2002) e Brito (2003) fazem referência à função de atender os agentes de mercado. Também funções como auditoria interna, citada por Jackson (1949) e Tung (1974), e controle interno, citada por Yoshitake (1984) e Horngren, Sundem e Stratton (2004), fazem parte, segundo os autores, das atribuições da controladoria.

Observa-se que, ao mesmo tempo em que há pontos em comum entre a maioria dos autores, também há, na literatura, entendimentos diversos sobre a amplitude. Constata-se certa assimetria sobre qual seja o campo de estudo e atuação da controladoria e, principalmente, sobre suas funções. Para Carvalho (1995, p. 3), a confusão de conceitos e visões encontra ressonância nos estudos acadêmicos, uma vez que ainda são grandes as incertezas do que vem a ser e compor efetivamente esse campo de estudos. Borinelli (2006) destaca que os conteúdos dos textos da área abordam o tema sob prismas que, em algumas situações, nem parecem fazer parte da mesma teoria. Teixeira (2003) descreve que não há consenso entre os autores de quais seriam as funções básicas da controladoria.

Visando reconhecer um conjunto de funções básicas, Horváth (2006) descreve que se deve estudar aquelas oriundas de representações (órgãos) oficiais e/ou associações como a Financial Executives Institute (FEI), de relatórios sobre estudos empíricos e específicos de atividades, forma de organização e desenvolvimento da controladoria, de publicações sobre soluções típicas ou dignas de imitação oriundas da práxis, de manuais e/ou obras de referência e pesquisas em entidades de seleção e recrutamento de controllers.

Levando em consideração a dificuldade de fazer afirmações precisas sobre as funções básicas da controladoria e buscando dar uma resposta a esta questão, surge a seguinte pergunta de pesquisa: Quais são as funções evidenciadas pela FEI e por manuais e obras de referência na área de controladoria em diferentes países? Assim, o objetivo central deste artigo é a identificação das funções da controladoria em manuais e obras de referências dos Estados Unidos, Alemanha e Brasil.

\section{FUNÇÕES DA CONTROLADORIA}

As funções têm por objetivo orientar o campo de atuação de determinada área do conhecimento. São como a ação própria ou natural de um órgão, aparelho ou máquina. Por isto, o conceito de função está associado: 
a) ao estudo das organizações, onde Weber (1963) sintetiza os processos de autoridade e obediência, dentro de um determinado grupo, Taylor (1995) trata a administração como ciência e Fayol (1990) trata do processo administrativo;

b) aos estudos sobre o papel dos gerentes, onde Barnard (1983) trata das funções do executivo, Simon (1965) e Stewart (1982) tratam do processo decisório, Mintzberg (1995) associa as funções aos papéis dos gerentes, Luthans (2004) cuida do desempenho dos gerentes e Grova (1997) aborda os princípios de administração de alta performance.

$\mathrm{Na}$ literatura clássica encontra-se como principais funções o planejamento, organização, direção e controle, que resumidamente podem ser caracterizadas como:

a) planejamento - determinação de um plano de ação que forneça uma base estimativa do grau de sucesso provável, para que os objetivos traçados sejam atingidos;

b) organização - para que haja a execução dos planos é necessário uma estrutura que defina o tipo de organização requerido para o sucesso dessa execução;

c) direção - coordenação das divisões das tarefas, com indicação clara de autoridade, poder, responsabilidade e lealdade;

d) controle - função que mede o desempenho presente em relação a padrões esperados, com a devida correção, quando necessário.

Para entender melhor essa questão, na seqüência são apresentadas as funções da controladoria segundo obras e manuais dos Estados Unidos, Alemanha e Brasil.

\subsection{Obras Pesquisadas dos Estados Unidos}

A origem da institucionalização da função da controladoria nas empresas privadas, segundo Horváth (2006), é resultado da industrialização ocorrida nos EUA na metade do século XIX. Para Beuren (2002), o crescimento vertical e diversificado desses conglomerados demandou, por parte dos acionistas e gestores, um controle central em relação aos departamentos e divisões que rapidamente se espalhavam nos Estados Unidos e em outros países.

Atentas a estas movimentações do cenário econômico mundial e ao conseqüente aumento das demandas informacionais, as empresas foram em busca de maneiras de neutralizar seus efeitos negativos e ainda identificar potenciais vantagens competitivas. Neste sentido, em 1892, a General Electric Company tornou-se a primeira indústria que, formalmente, instituiu a posição de controller (HORVÁTH, 2006).

A partir de então, a preocupação dos norte-americanos com a controladoria ganhou força e importância no ambiente empresarial. Com isto, em 1946, surgiu a primeira versão das funções da controladoria de forma institucional. Foi elaborada pelo Controller's Institute of América com o título de The Place of the Controller's Office. Esta versão original continha 17 diferentes funções para o controller. Atualmente, este número foi reduzido a sete funções básicas, conforme evidenciado no Quadro 1.

Em uma visão mais tradicional, Heckert e Willson (1963) definem como funções do controller a supervisão da contabilidade geral e de custos, auditoria, impostos, seguros e estatísticas, e aplicações da função contábil para prevenção de futuros problemas administrativos. Assim, enfatiza a aplicação de dados contábeis para as futuras atividades da organização e dá um enfoque analítico à administração do sistema de planejamento e controle.

Na visão de Jackson (1949), a função básica do controller continua sendo a de extrair da contabilidade informações para dar suporte à tomada de decisão dos administradores. Heckert e Willson (1963) destacam aspectos da contabilidade, como o planejamento via processo orçamentário. Já Anderson, Schmidt e McCosh (1973) expandem as funções do 
controller ao processamento de informações de um modo geral, ou seja, ele passa a ser responsável pela geração das informações. Para os autores, a contabilidade interage e dá suporte ao planejamento da organização.

Desde meados de 1990, percebe-se na literatura especializada americana a migração da orientação essencialmente voltada à contabilidade para uma abordagem mais direcionada às estratégias. Assim, o desenvolvimento da controladoria partiu da contabilidade para uma ampla função de informação, passando à orientação das estratégias e focalizando a implementação e transformação das estratégias em medidas operacionais, não sendo mais tratada em livro próprio, mas em livros de Controle Gerencial, de Anthony e Govindarajan (2002), e Contabilidade Gerencial, de Horngren, Sundem e Stratton (2004), entre outros.

\subsection{Obras Pesquisadas da Alemanha}

Enquanto nos EUA os primeiros registros sobre as funções da controladoria reportam ao final do século XIX, na República Federal da Alemanha a expansão do tema começou no fim dos anos de 1950. Depois de uma restrição inicial, ocorreu um crescimento rápido em muitas organizações na década seguinte (KÜPPER, 2005). Possivelmente impulsionadas pelo novo contexto organizacional que começava a se desenhar na segunda metade daquela década.

Em 1963, Bussmann, em seu livro de Contabilidade Industrial, dedicou um capítulo ao controller. Entretanto, somente a partir de 1970 as primeiras obras específicas de controladoria surgiram, como a de Mann (1973). O Quadro 1 mostra uma lista de funções da área, de acordo com obras pesquisadas da Alemanha.

Conforme evidenciado no Quadro 1, dois autores alemães fazem referência às funções do Instituto dos Executivos em Finanças (SERFLING, 1992; SCHWARZ, 2002), enquanto nas obras dos demais autores há uma homogeneidade nas definições.

Na visão de Horváth (2006), a controladoria na Alemanha trata-se de uma experiência prática, sobre uma função de coordenação amplamente desenvolvida e atualmente muito difundida no meio empresarial. Nela, o profissional desta área tem a função de transformar a seqüência de acontecimentos em resultados.

Em decorrência desta visão prática e alinhada, percebe-se uma ampla abertura para a participação da controladoria no planejamento em todos os níveis. Por outro lado, as funções orientadas para finanças raramente são associadas com a área.

\subsection{Obras Pesquisadas do Brasil}

No Brasil não se tem uma data precisa para o surgimento do termo controladoria e controller. Provavelmente, deve-se à vinda das grandes corporações internacionais, entretanto, as funções que ela engloba já existiam antes, mas não com esta epistemologia.

Ao analisar o contexto nacional, há dois momentos distintos no desenvolvimento da controladoria: antes e depois das pesquisas sobre o GECON. Em geral, os autores anteriores, como Tung (1974), Kanitz (1976) e Yoshitake (1984), quando definem controladoria e suas funções buscam apoiar-se em autores norte-americanos. Por exemplo, Tung (1974) faz referência às 17 funções básicas do Controllers Institute of América. Já quanto às qualidades do controller, faz referência ao trabalho de Heckert e Willson (1963).

Por outro lado, os estudiosos do tema posteriores às pesquisas do Professor Armando Catelli foram fortemente influenciados pelo Modelo da Gestão Econômica (GECON), criado pela equipe de pesquisadores da Faculdade de Economia, Administração e Contabilidade da Universidade de São Paulo.

O desenvolvimento do sistema de gestão econômica começou com as reflexões do Professor Armando Catelli no final dos anos de 1970 (SANTOS, 2005). Estes trabalhos 
produziram uma série de dissertações e teses, além de artigos e livros que influenciaram e continuam sendo referência nas pesquisas sobre controladoria no Brasil.

Mesmo assim, autores deste período, como Mosimann e Fisch (1999) e Padoveze e Benedicto (2005), referenciam autores norte-americanos como Heckert e Willson (1963), dentre outros. Isto mostra que a influência norte-americana permanece neste período.

O Quadro 1 resume as funções de controladoria extraídas das obras pesquisadas dos três países, em que, na primeira coluna evidenciam-se as principais funções identificadas e, nas demais apresentam-se os autores das obras, com uma coluna de totalização da frequiência de citação de cada função, nos três países e no total das obras e autores pesquisados.

\begin{tabular}{|c|c|c|c|c|c|c|c|c|c|c|c|c|c|c|c|c|c|c|c|c|c|}
\hline País & AUTORES & 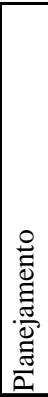 & $\begin{array}{l}0 \\
0 \\
0 \\
0 \\
0 \\
0 \\
0\end{array}$ & 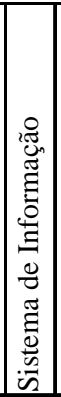 & 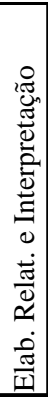 & 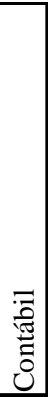 & 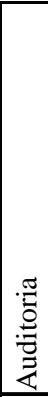 & 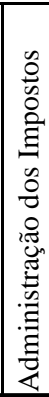 & $\mid \begin{array}{c}0 \\
0 \\
0 \\
0 \\
0 \\
0 \\
0 \\
0 \\
0 \\
0 \\
0\end{array}$ & 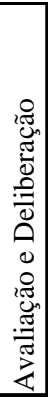 & 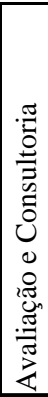 & 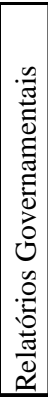 & 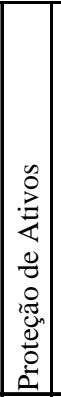 & $\begin{array}{l}0 \\
0 \\
0 \\
0 \\
0 \\
0 \\
0 \\
0 \\
0 \\
0 \\
0 \\
\Xi \\
0 \\
0 \\
0 \\
0 \\
0 \\
0 \\
0 \\
0\end{array}$ & 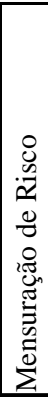 & 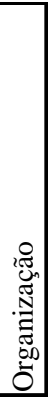 & 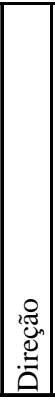 & 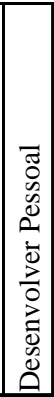 & 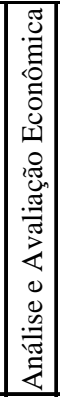 & 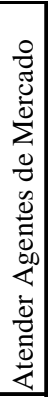 & 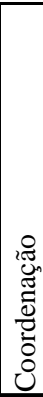 \\
\hline \multirow{11}{*}{ 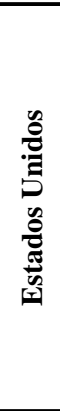 } & Jackson (1949) & & & & $\mathrm{X}$ & $\mathrm{X}$ & $\mathrm{X}$ & $\mathrm{X}$ & & & & & & & & & & & & & \\
\hline & Financial Executives Institute (1962) & $\mathrm{X}$ & & & $\mathrm{X}$ & & & $\mathrm{X}$ & & $\mathrm{X}$ & & $\mathrm{X}$ & $\mathrm{X}$ & & & & & & $\mathrm{X}$ & & \\
\hline & Cohen e Robbins (1966) & $\mathrm{X}$ & $\mathrm{X}$ & & & & & $\mathrm{X}$ & & & $\mathrm{X}$ & $\mathrm{X}$ & $\mathrm{X}$ & & & & & & $\mathrm{X}$ & $\mathrm{X}$ & \\
\hline & Heckert e Willson (1963) & $\mathrm{X}$ & $\mathrm{X}$ & & $\mathrm{X}$ & $\mathrm{X}$ & & & & & & & & & & & & & $\mathrm{X}$ & & \\
\hline & Vancil (1970) & $\mathrm{X}$ & $\mathrm{X}$ & & & $\mathrm{X}$ & & & & & & & & $\mathrm{X}$ & & & & & & & \\
\hline & Anderson, Schmidt e McCosh (1973) & & $\mathrm{X}$ & & $\mathrm{X}$ & $\mathrm{X}$ & & & & & & & $\mathrm{X}$ & & $\mathrm{X}$ & & & & & & \\
\hline & Willson e Colford (1981) & $\mathrm{X}$ & $\mathrm{X}$ & & $\mathrm{X}$ & & $\mathrm{X}$ & $\mathrm{X}$ & & & & & & & & & & & & & \\
\hline & Roehl-Anderson e Bragg (1996) & $\mathrm{X}$ & & & & $\mathrm{X}$ & & & & & & & & & & $\mathrm{X}$ & $\mathrm{X}$ & & & & \\
\hline & Anthony e Govindarajan (2002) & $\mathrm{X}$ & $\mathrm{X}$ & & $\mathrm{X}$ & & $\mathrm{X}$ & & $\mathrm{X}$ & & & & $\mathrm{X}$ & & & & & $\mathrm{X}$ & $\mathrm{X}$ & & \\
\hline & Horngren, Sundem e Stratton (2004) & $\mathrm{X}$ & $\mathrm{X}$ & & $\mathrm{X}$ & & & & & & & & \begin{tabular}{|l|l|}
$X$ \\
\end{tabular} & & & & & & $\mathrm{X}$ & & \\
\hline & Sub-Total (EUA) & 8 & 7 & 0 & 7 & 5 & 3 & 4 & 1 & 1 & 1 & 2 & 5 & 1 & 1 & 1 & 1 & 1 & 5 & 1 & 0 \\
\hline \multirow{11}{*}{ 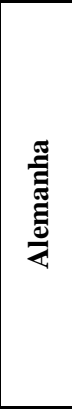 } & Mann (1973) & $\mathrm{X}$ & $\mathrm{X}$ & $\mathrm{X}$ & & & & & & & & & & & & & & & & & \\
\hline & Bramsemann (1980) & $\mathrm{X}$ & $\mathrm{X}$ & $\mathrm{X}$ & & & & & & & & & & & & $\mathrm{X}$ & & & & & \\
\hline & Welge (1988) & $\mathrm{X}$ & $\mathrm{X}$ & $\mathrm{X}$ & & & & & & $\mathrm{X}$ & & & & & & & & & & & \\
\hline & Serfling (1992) & $\mathrm{X}$ & & & $\mathrm{X}$ & & & & & & $\mathrm{X}$ & & $\mathrm{X}$ & & & & & & $\mathrm{X}$ & $\mathrm{X}$ & \\
\hline & Reichmann (2001) & $\mathrm{X}$ & $\mathrm{X}$ & $\mathrm{X}$ & & & & & & & & & & & & & & & & & $\mathrm{X}$ \\
\hline & Hahn (2001) & $\mathrm{X}$ & $\mathrm{X}$ & $\mathrm{X}$ & & & & & & & & & & & & & $\mathrm{X}$ & & & & $\mathrm{X}$ \\
\hline & Schwarz (2002) & $\mathrm{X}$ & & & $\mathrm{X}$ & & & & & & $\mathrm{X}$ & & $\mathrm{X}$ & & & & & & $\mathrm{X}$ & $\mathrm{X}$ & \\
\hline & Weber (2004) & $\mathrm{X}$ & $\mathrm{X}$ & $\mathrm{X}$ & & & & & & & & & & & & & & & & & $\mathrm{X}$ \\
\hline & Küpper (2005) & $\mathrm{X}$ & $\mathrm{X}$ & $\mathrm{X}$ & & & & & & & & & & & & $\mathrm{X}$ & & $\mathrm{X}$ & & & \\
\hline & Horváth (2006) & $\mathrm{X}$ & $\mathrm{X}$ & $\mathrm{X}$ & & & & & & & & & & & & & $\mathrm{X}$ & & & & $\mathrm{X}$ \\
\hline & Sub-Total (Alemanha) & 10 & 8 & 8 & 2 & 0 & 0 & 0 & 0 & 1 & 2 & 0 & 2 & 0 & 0 & 2 & 2 & 1 & 2 & 2 & 4 \\
\hline \multirow{12}{*}{ 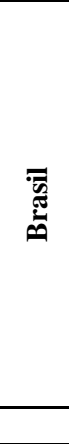 } & Tung (1974) & $\mathrm{X}$ & $\mathrm{X}$ & & $\mathrm{X}$ & $\mathrm{X}$ & $\mathrm{X}$ & & & & & & & $\mathrm{X}$ & & & & & & & \\
\hline & Kanitz (1976) & $\mathrm{X}$ & $\mathrm{X}$ & $\mathrm{X}$ & & $\mathrm{X}$ & & & & $\mathrm{X}$ & & & & & & & & & & & \\
\hline & Yoshitake (1984) & & $\mathrm{X}$ & & $\mathrm{X}$ & $\mathrm{X}$ & & & & & & & \begin{tabular}{|l|l|}
$X$ \\
\end{tabular} & & $\mathrm{X}$ & & & & & & \\
\hline & Mossiman e Fisch (1999) & $\mathrm{X}$ & $\mathrm{X}$ & & $\mathrm{X}$ & $\mathrm{X}$ & & & & & & & & & & & & & & & \\
\hline & \begin{tabular}{|l} 
Almeida, Parisi e Pereira (2001) \\
\end{tabular} & $\mathrm{X}$ & $\mathrm{X}$ & $\mathrm{X}$ & & & & & & $\mathrm{X}$ & & & & & & & & & $\mathrm{X}$ & $\mathrm{X}$ & \\
\hline & \begin{tabular}{|l} 
Peleias (2002) \\
\end{tabular} & $\mathrm{X}$ & $\mathrm{X}$ & $\mathrm{X}$ & & & & & & & & & & & & & & & & $\mathrm{X}$ & \\
\hline & Beuren (2002) & & $\mathrm{X}$ & $\mathrm{X}$ & & & & & & & & & & & & & $\mathrm{X}$ & & & & \\
\hline & Brito (2003) & $\mathrm{X}$ & $\mathrm{X}$ & & $\mathrm{X}$ & $\mathrm{X}$ & & & & & & & & & & & & & & $\mathrm{X}$ & \\
\hline & Padoveze e Benedicto (2005) & $\mathrm{X}$ & $\mathrm{X}$ & & $\mathrm{X}$ & $\mathrm{X}$ & & & & & & & & & & & & & & & \\
\hline & Nascimento e Reginato (2007) & $\mathrm{X}$ & $\mathrm{X}$ & $\mathrm{X}$ & & & & & & & $\mathrm{X}$ & & & & & & & & & & \\
\hline & Sub-Total (Brasil) & 8 & 10 & 5 & 5 & 6 & 1 & 0 & 0 & 2 & 1 & 0 & 1 & 1 & 1 & 0 & 1 & 0 & 1 & 3 & 0 \\
\hline & Total & 26 & 25 & 13 & 14 & 11 & \begin{tabular}{|l|}
4 \\
\end{tabular} & 4 & 1 & 4 & \begin{tabular}{|l|}
4 \\
\end{tabular} & 2 & 8 & 2 & 2 & 3 & 4 & 2 & 8 & 6 & 4 \\
\hline
\end{tabular}

Quadro 1 - Funções da controladoria de acordo com obras e manuais de referência dos Estados Unidos, Brasil e Alemanha.

Fonte: dados da pesquisa. 


\section{METODOLOGIA DE PESQUISA}

Ao ingressar no campo da pesquisa científica, constata-se que diversas são as linhas existentes, bem como os resultados delas decorrentes. A forma de organização, investigação e análise dependem do quadro de referência adotado pelos pesquisadores bem como da questão que orienta o trabalho. Assim, a definição do arcabouço metodológico a adotar constitui-se numa questão-chave, pois ele comporá o pano de fundo que norteará a pesquisa. Não dar a devida atenção a esta questão implica incorrer no que Sokal e Bricmont (2001) denominam de imposturas intelectuais.

Nesta perspectiva o presente estudo se pauta num trabalho investigativo do referencial teórico que aborda o tema da controladoria. Para tanto, com base na frequiência das citações e relevância das suas contribuições, foram selecionadas dez obras e manuais de cada um dos países a serem estudados. Em seguida, com base no referencial teórico adotado, foi realizado um estudo buscando identificar, na perspectiva dos autores selecionados, as bases que definem as funções da controladoria.

Desta forma, por ter como propósito a observação, classificação, registro e evidenciação dos resultados, a metodologia da pesquisa adotada é, de acordo com Andrade (2002), descritiva quanto ao seu objetivo, pois, preocupa-se em observar, registrar, analisar, classificar e interpretar os fatos, sem a interferência dos pesquisadores. Ou seja, os fenômenos do mundo físico e humano são estudados, mas não manipulados pelo pesquisador.

Quanto aos procedimentos, a pesquisa é bibliográfica e documental. Nesta linha, Gil (1999) descreve que este tipo de procedimento tem como pano de fundo a idéia de pautar seu desenvolvimento sobre material já elaborado, principalmente livros e artigos científicos. No entanto, o estudo também utiliza-se da pesquisa documental. Desta forma, com base nestas investigações, busca-se fazer primeiramente uma breve apresentação das funções da controladoria sob a visão dos pesquisadores de dois países com importante papel no desenvolvimento do tema, os Estados Unidos e a Alemanha, além do Brasil.

Por fim, quanto à abordagem, a pesquisa pode ser considerada predominantemente qualitativa, uma vez que se caracteriza pela não utilização de instrumentos estatísticos. Isto porque Richardson (1999) define a pesquisa qualitativa como sendo estudos que procuram descrever a complexidade de determinado problema, analisar a interação de certas variáveis e compreender e classificar processos dinâmicos vividos por grupos sociais.

\section{DISCUSSÕES DA PESQUISA}

A partir do Quadro 1, elaborou-se a Tabela 1, na qual se evidenciam as funções mais referenciadas nas obras pesquisadas. Na Tabela 1 constata-se que, no Brasil, 100\% das obras analisadas julgam que o planejamento é função da controladoria. Nos Estados Unidos e na Alemanha, esta é a opinião de $80 \%$ das obras pesquisadas. Com relação à função de controle percebe-se que, na Alemanha, é considerada como sendo de responsabilidade da controladoria por $100 \%$ dos autores. Por seu turno, no Brasil e nos Estados Unidos, esta é a opinião de $80 \%$ e $70 \%$ dos autores pesquisados, respectivamente.

Se forem consideradas as definições clássicas das funções planejamento, organização, direção e controle, denota-se que nos três países há um consenso sobre a importância do papel do controller como agente de pensar no futuro da organização (planejamento) e de monitorar e corrigir a rota (controle).

Entre as funções com menor referência, destacam-se o controle interno com 3\%, relatórios governamentais, processamento de dados, mensuração do risco e desenvolvimento de pessoas com 7\%, respectivamente. Adicionalmente, são pouco citadas as funções relacionadas a processamento de dados, substituído pelo termo sistemas de informações e auditoria interna. 
Tabela 1 - Funções da controladoria mais citadas

\begin{tabular}{|c|c|c|c|c|c|c|c|c|}
\hline \multirow[b]{2}{*}{ FUNÇÃO } & \multicolumn{2}{|c|}{ EUA } & \multicolumn{2}{|c|}{ ALEMANHA } & \multicolumn{2}{|c|}{ BRASIL } & \multicolumn{2}{|c|}{$\begin{array}{l}\text { TOTAL } \\
\text { GERAL }\end{array}$} \\
\hline & $\mathbf{N}^{\mathbf{0}}$ & $\%$ & № & $\%$ & $\mathbf{N}^{\mathbf{0}}$ & $\%$ & № & $\%$ \\
\hline Planejamento & 8 & 80 & 8 & 80 & 10 & 100 & 26 & 87 \\
\hline Controle & 7 & 70 & 10 & 100 & 8 & 80 & 25 & 83 \\
\hline Sistema de Informação & 0 & 0 & 5 & 50 & 8 & 80 & 13 & 43 \\
\hline Elaboração Relat.e Interpretação & 7 & 70 & 5 & 50 & 2 & 20 & 14 & 47 \\
\hline Contábil & 5 & 50 & 6 & 60 & 0 & 0 & 11 & 37 \\
\hline Auditoria & 3 & 30 & 1 & 10 & 0 & 0 & 4 & 13 \\
\hline Administração dos Impostos & 4 & 40 & 0 & 0 & 0 & 0 & 4 & 13 \\
\hline Controle Interno & 1 & 10 & 0 & 0 & 0 & 0 & 1 & 3 \\
\hline Avaliação e Deliberação & 1 & 10 & 2 & 20 & 1 & 10 & 4 & 13 \\
\hline Avaliação e Consultoria & 1 & 10 & 1 & 10 & 2 & 20 & 4 & 13 \\
\hline Relatórios Governamentais & 2 & 20 & 0 & 0 & 0 & 0 & 2 & 7 \\
\hline Proteção de Ativos & 5 & 50 & 1 & 10 & 2 & 20 & 8 & 27 \\
\hline Processamento de Dados & 1 & 10 & 1 & 10 & 0 & 0 & 2 & 7 \\
\hline Mensuração de Risco & 1 & 10 & 1 & 10 & 0 & 0 & 2 & 7 \\
\hline Organização & 1 & 10 & 0 & 0 & 2 & 20 & 3 & 10 \\
\hline Direção & 1 & 10 & 1 & 10 & 2 & 20 & 4 & 13 \\
\hline Desenvolver Pessoal & 1 & 10 & 0 & 0 & 1 & 10 & 2 & 7 \\
\hline Análise e Avaliação Econômica & 5 & 50 & 1 & 10 & 2 & 20 & 8 & 27 \\
\hline Atender Agentes de Mercado & 1 & 10 & 3 & 30 & 2 & 20 & 6 & 20 \\
\hline Coordenação & 0 & 0 & 0 & 0 & 4 & 40 & 4 & 13 \\
\hline
\end{tabular}

Fonte: dados da pesquisa.

Percebe-se também que funções como a contábil, auditoria, administração de impostos, controle interno, mensuração do risco, entre outras, não integram o rol de atividades da controladoria na Alemanha. Neste país a controladoria exerce função mais sistêmica e estratégica, participando ativamente do planejamento e controle estratégico e do sistema de informação.

Por seu turno, na literatura americana constata-se a mudança da orientação contábil para uma orientação mais estratégica. Isto deve-se particularmente aos trabalhos de Kaplan e Norton (1992, 1996, 1997, 2000, 2001, 2004 e 2006) sobre o Balanced Scorecard e de Simons (1995 e 2000) sobre as Levers of Control e Performance Measurement, que colocam a avaliação de desempenho com medidas não financeiras no centro da discussão.

$\mathrm{Na}$ Alemanha nota-se uma acepção entre os autores quanto às funções de planejamento, seguida por controle e sistemas de informações, exceto para Serfling (1992) e Schwarz (2002). Assim, funções relacionadas a contabilidade, tributos e auditoria não fazem parte da plataforma das obras pesquisadas de controladoria.

No Brasil, ainda não se consegue perceber uma orientação clara sobre as funções da controladoria. Conseqüentemente, a plataforma teórica do tema carece de mais pesquisas para que num futuro próximo, possam estar mais consolidadas, como na Alemanha.

A fim de particularizar as funções básicas conforme as diversas obras pesquisadas, segue no Quadro 2 uma representação das funções básicas agrupadas segundo abordagens. As funções relacionadas com a abordagem da gestão operacional são fortemente influenciadas pela visão das funções da controladoria do Controller's Institute of América, de 1946. Autores como Jackson (1949), Heckert e Willson (1963), Cohen e Robbins (1966), Vancil (1970), Anderson, Schmidt e McCosh (1973), Tung (1974), Willson e Colford (1981), Yoshitake 
(1984), Serfling (1992), Roehl-Anderson e Bragg (1996), Schwarz (2002), Horngren, Sundem e Stratton (2004), Brito (2003) e Padoveze e Benedicto (2005), apresentam forte alinhamento no enquadramento da primeira abordagem.

\begin{tabular}{|c|c|}
\hline Abordagens & Funções Básicas \\
\hline Gestão Operacional & $\begin{array}{ll} & \text { Planejamento (Operacional) } \\
\text { a } & \text { Elaboração de relatórios e interpretação } \\
\text { a } & \text { Avaliação e deliberação } \\
\text { a } & \text { Administração de impostos } \\
\text { a } & \text { Elaboração de relatórios a órgãos reguladores e públicos } \\
\text { 口 } & \text { Proteção do patrimônio } \\
\square & \text { Avaliações da economia política }\end{array}$ \\
\hline Gestão Econômica & $\begin{array}{ll} & \text { Subsidiar o processo de gestão } \\
\square & \text { Apoiar a avaliação de desempenho } \\
\square & \text { Apoiar a avaliação de resultado } \\
\square & \text { Gerir o sistema de informações } \\
\square & \text { Atender aos agentes de mercado. }\end{array}$ \\
\hline Gestão Estratégica & $\begin{array}{ll} & \text { Planejamento } \\
\text { 口 } & \text { Sistema de informações } \\
\text { a } & \text { Controle } \\
\text { a } & \text { Gestão de pessoas } \\
\square & \text { Organizacional }\end{array}$ \\
\hline
\end{tabular}

Quadro 2 - Relação das funções básicas da controladoria

Fonte: dados da pesquisa.

O grupo dos representantes da segunda abordagem, gestão econômica, basicamente é formado por autores brasileiros influenciados pelas idéias do GECON. Assim, entre estes autores destacam-se Mosimann e Fisch (1999), Almeida, Parisi e Pereira (2001), Peleias (2002) e Santos (2005), entre outros.

$\mathrm{Na}$ terceira perspectiva, gestão estratégica, encontram-se autores norte-americanos, como Anthony e Govindarajan (2001), que entendem que a controladoria desempenha um importante papel na preparação de planos estratégicos e orçamentários. Adicionalmente, Atkinson et al. (2000) e Garrison e Noreen (2001) defendem que no atual contexto a controladoria está se tornando parte da alta administração, participando da formulação e implementação de estratégias, cabendo-lhe a tarefa de traduzir o plano estratégico em medidas operacionais e administrativas.

Entre os autores brasileiros simpatizantes desta abordagem encontram-se Mosimann e Fisch (1999), Almeida, Parisi e Pereira (2001), Peleias (2002), Schmidt e Santos (2006) e Nascimento e Reginato (2007). Já os autores alemães, como Mann (1973), Bramsemann (1980), Welge (1988), Reichmann (2001), Hahn (2001), Weber (2004), Küpper (2005) e Horváth (2006), defendem que a controladoria deve atuar em um papel mais sistêmico, o que inclui a coordenação do planejamento e controle estratégico da organização.

Constata-se, assim, que há diversas abordagens e visões sobre o que seja controladoria e quais suas funções. Porém, entende-se que elas não são conflitantes, e que podem, inclusive, ser complementares, constituindo-se partes do todo.

De acordo com Lunkes e Schnorrenberger (2009), a controladoria evoluiu de uma função de controle financeiro para uma área mais ampla, com inclusão da contabilidade, planejamento e controle e sistemas de informações. Há também funções que tiveram alterações, em decorrência da própria evolução tecnológica como, por exemplo, processamento de dados para sistemas de informações. A Figura 1 apresenta a percepção sobre a evolução desta área. 


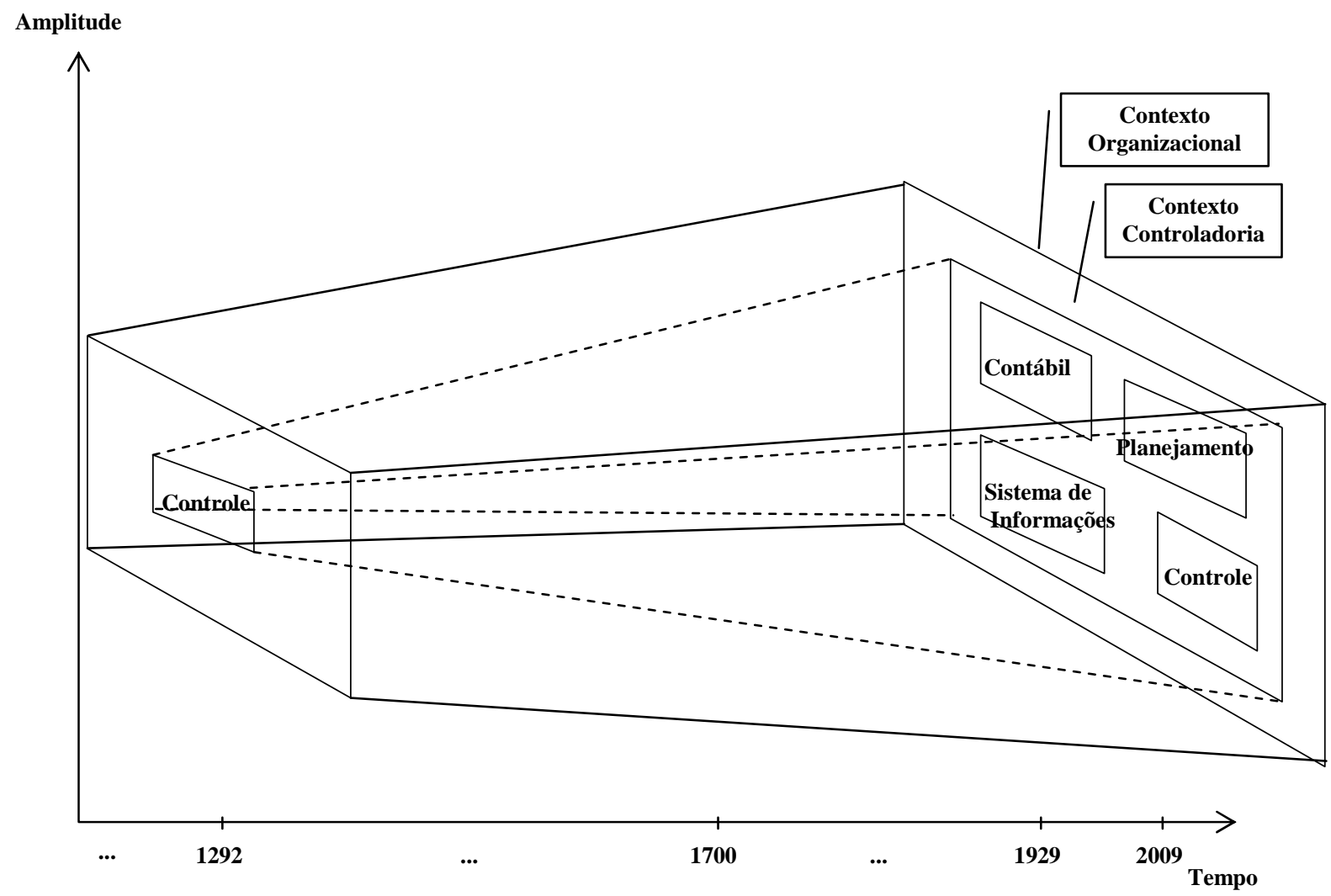

Figura 1 - Evolução do campo de atuação da Controladoria Fonte: Lunkes e Schnorrenberger (2009).

Conforme ilustra a Figura 1, o espectro da controladoria foi sendo ampliado ao longo do tempo. Originalmente estava fortemente amparada no controle, conseqüentemente, sua base se encontrava na contabilidade. Ao longo do tempo, com o aumento da complexidade nas organizações, este espectro foi sendo ampliado e novas áreas de preocupação foram sendo incorporadas como, planejamento e sistema de informações. Convém destacar também, que esta evolução não ocorreu de maneira linear. Ela se fez mais presente principalmente nos momentos de crise. Cabe também observar que estudos de práticas isoladas não podem ser usados como base para a definição das funções da controladoria, e que um arcabouço maior de publicações pode refletir mais adequadamente o estado da arte e a necessidade da atividade na prática.

\section{CONCLUSÕES}

Ao longo deste estudo constatou-se que há obras que abordam as funções da controladoria de forma não inteligível, gerando muitas vezes pontos de vista antagônicos e confusos para o leitor. Há também, especialmente no Brasil, autores que estão buscando definições de termos do passado, tentando reviver a nostalgia da contabilidade; incluindo citações da FEI que já foram alteradas há décadas.

Há também modismos que relacionam todas as funções de uma organização, métodos e ferramentas, ao termo. Esta postura resulta num conjunto de elementos associados ao tema, fazendo com que o foco seja desviado. Assim, são publicados livros que contemplam no seu título o termo Controladoria, mas seu conteúdo nada lembra a essência do tema, muito menos tem relação com pesquisas ou nomenclaturas de outros países. Também artigos ou pesquisas são publicados sem o tratamento metodológico adequado para um melhor entendimento do leitor e aferição de conclusões que possam contribuir para o avanço dos estudos na área. 
Por fim, apesar dos desvios constatados na literatura, pode-se afirmar que há algumas funções que estão bem próximas ao consenso. Destacam-se as funções de planejamento e controle que são apontadas como sendo da controladoria por $87 \%$ e $83 \%$ das obras pesquisadas, respectivamente. Isto indica que grande parte das preocupações da controladoria devem estar mais voltadas para o futuro da organização. Ou seja, espera-se que o controller tenha uma postura proativa em relação à organização e não apenas informativa.

Para isso, ele deve ter a qualificação adequada para cumprir as funções acima relacionadas. A análise das funções da controladoria, na percepção de diferentes obras publicadas no Brasil, Alemanha e Estados Unidos, realizada neste trabalho, demonstra uma riqueza de apontamentos das funções do controller e, portanto, das qualificações exigidas para bom exercício dessa atividade.

\section{REFERÊNCIAS}

ALMEIDA, L. B.; PARISI, C.; PEREIRA, C. A. Controladoria. In: CATELLI, A. (Coord.). Controladoria: uma abordagem da gestão econômica - GECON. 2. ed. São Paulo: Atlas, 2001.

ANDERSON, D.R.; SCHMIDT, L.A.; MCCOSH. A.M. Practical controllership. 3. ed. Howewood, 1973.

ANDRADE, Maria Margarida de. Introdução à metodologia do trabalho científico: elaboração de trabalhos na graduação. São Paulo: Atlas, 2002.

ANSOFF, H. I. Managing strategic surprise by response to weak signals. California Management Review, v.18, p. 21-33, 1975.

ANTHONY. Robert N.; GOVINDARAJAN, Vijay. Sistemas de controle gerencial. São Paulo: Atlas, 2001.

ATKINSON, Anthony A. et al. Contabilidade gerencial. São Paulo: Atlas, 2000.

BEUREN, Ilse M.. O papel da Controladoria no processo de Gestão. In: Paulo Schmidt. Controladoria: agregando valor para a empresa. Porto Alegre: Bookmann, p.15-38, 2002.

BORINELLI, Márcio L. Estrutura básica conceitual de controladoria: sistematização à luz da teoria e da prática. São Paulo: FEA/USP, 2006. Tese (Doutorado em Ciências Contábeis) Faculdade de Economia, Administração e Contabilidade da Universidade de São Paulo, São Paulo, 2006.

BRAMSEMANN, Reiner. Handbuch controlling: methoden und techniken. 2. ed. Auflage, Müchen, 1980.

BRITO, Osias. Controladoria de risco: retorno em instituições financeiras. São Paulo: Saraiva, 2003.

CARVALHO, Marcelino F. Uma contribuição ao estudo da controladoria em instituições financeiras organizadas sob a forma de múltiplo Banco. São Paulo: FEA/USP, 1995. Dissertação (Mestrado em Ciências Contábeis) - Faculdade de Economia, Administração e Contabilidade da Universidade de São Paulo, São Paulo, 1995.

COHEN, J.B., ROBBINS, S.M. The financial manager: basic aspects of financial Administration. New York: Evanston \& London, 1966.

CORONADO, Osmar. Controladoria no atacado e varejo. São Paulo: Atlas, 2001.

FAYOL, Henry. Administração industrial e geral: previsão, organização, comando, coordenação e controle. 10 ed. São Paulo: Atlas, 1990. 
FIGUEIREDO, S.; CAGGIANO, P. C. Controladoria: teoria e prática. São Paulo: Atlas, 1997.

GARRISON, Ray H.; NOREEN Eric W. Contabilidade gerencial. 9. ed. Rio de Janeiro: LTC, 2001.

GIL, Antônio C. Métodos e técnicas de pesquisa social. 5. ed. São Paulo: Atlas, 1999.

GROVE, Andrew. S. Administração da alta performance. São Paulo: Futura, 1997.

HAHN, D.; HUNGENBERG, H. Puk-wertorientierte controllingkonzepte. 6. ed. Wiesbaden, 2001.

HECKERT, J.B.; WILLSON, James D. Controllership. New York: Ronald Press Co, 1963.

HORNGREN, Charles T.; FOSTER, George; DATAR, Krikant M. Contabilidade de custos. 9. ed. Rio de Janeiro: LTC, 1997.

HORNGREN, Charles T.; SUNDEM Gary L., STRATTON, Willian O. Contabilidade gerencial. 12. ed. São Paulo: Pearson, 2004.

HORVÀTH, Péter. Controlling. 10. ed. München: Verlag Vahlen, 2006.

JACKSON, J. H. The comptroller: his function and organization. Cambridge: Mass, 1949.

KANITZ, Stephen C. Controladoria: teoria e estudo de casos. São Paulo: Pioneira, 1976.

KAPLAN, Robert S.; NORTON, David P. A estratégia em ação: balanced scorecard. 7. ed. Rio de Janeiro: Campus, 1997.

KAPLAN, Robert S.; NORTON, David P. A organização orientada para a estratégia: como as empresas que adotam o balanced scorecard prosperam no novo ambiente de negócios. 3. ed. Rio de Janeiro: Campus, 2001.

KÜPPER, Peter. Controlling: konzeption, aufgaben und instrumente. 4. ed. Auflage. Berlin: MSG, 2005.

LUNKES, Rogério J.; SCHNORRENBERGER, Darci. Controladoria: na coordenação dos sistemas de gestão. São Paulo: Atlas, 2009.

LUTHANS, Fred. Organizational behavior. 10. ed. New York: McGraw-Hill/Irwin, 2004.

MANN, R. Die práxis des controlling. München, 1973.

MINTZBERG, Henry. Criando organizações eficazes: estruturas em cinco configurações. São Paulo: Atlas, 1995.

MOSIMANN, C. P.; FISCH, S. Controladoria. 2. ed. São Paulo: Atlas, 1999.

NAKAGAWA, Masayuki. Introdução à controladoria: conceitos, sistemas, implementação. São Paulo: Atlas, 1993.

NASCIMENTO, Auster M.; REGINATO, Luciane. Controladoria: um enfoque eficácia organizacional. São Paulo: Atlas, 2007.

OLIVEIRA, L.; PEREZ JUNIOR, J.; SILVA, C. Controladoria estratégica. 2. ed. São Paulo: Atlas, 2004.

PADOVEZE, Clóvis L., BENEDICTO, Gideon C. Controladoria Avançada (In: Clóvis L. Padoveze). São Paulo: Thomson, 2005.

PELEIAS, Ivam Ricardo. Controladoria: gestão eficaz utilizando padrões. São Paulo: Saraiva, 2002. 
REICHMANN, Thomas. Controlling und managementberichten. 6. ed. Auflage, München, 2001.

RICHARDSON, Roberto Jarry. Pesquisa social: métodos e técnicas. 3. ed. São Paulo: Atlas, 1999.

ROEHL-ANDERSON, Janice M.; BRAGG, Steven M. The controller's function: the work of the managerial accounting. New York: John Wiley \& Sons, 1996.

SANTOS, Roberto V. Controladoria: uma introdução ao sistema de gestão econômica Gecon. São Paulo: Saraiva, 2005.

SCHWARZ, Wolfgang U. Controlling: stragische unternehmensführung, München, 2002.

SERFLING, Klaus. Controlling. 2. ed. Auflage, Stuttgart, 1992.

SIEGEL, G.; KULESZA, C. From statement preparer to decision-support specialist: the coming changes in management accounting education. Management Accounting, Jan. 1996.

SIMONS, Robert. Levers of control: how managers use innovative control systems to drive strategic renewal. Boston: Harvard Business, 1995.

SIMONS, Robert. Performance measurement \& control systems for implementing strategy. New Jersey: Prentice Hall, 2000.

SOKAL, A.; BRICMONT, J. Imposturas intelectuais: o abuso da ciência pelos filósofos pós-modernistas. Rio de Janeiro: Record, 2001.

STEWART, Rosemary. Choises for the manager. London: McGrawwHill, 1982.

TAYLOR, Frederick W. Princípios de administração científica. São Paulo: Atlas, 1995.

TEIXEIRA, Olimpio C. Contribuição ao estudo das funções e responsabilidades do controller nas organizações. São Paulo: FEA/USP, 2003. Dissertação (Mestrado em Ciências Contábeis) - Faculdade de Economia, Administração e Contabilidade da Universidade de São Paulo, São Paulo, 2003.

TUNG, Nguyen H. Controladoria financeira das empresas: uma abordagem prática. 8. ed. São Paulo: Editora da Universidade de São Paulo, 1974.

VANCIL, R. F. Controlling. Homewood: Schäffer, 1970.

YOSHITAKE, Mariano. Manual de controladoria financeira. São Paulo: IOB Informações Objetivas, 1984.

WEBER, Jürgen. Einführung in das controlling. 10. ed. Nördlingen: Schäffer Poeschel, 2004.

WEBER, Max. Os fundamentos da organização burocrática: uma construção do tipo ideal, 1963.

WELGE, Martin K. Controlling. Stuttgart: Schäffer, 1988.

WILLSON, J.D.; COLFORD, J.P. Controllership. 3. ed. New York, 1981.

ZIMMERMAN, Jerold L. Accounting for decision making and control. 3. ed. New York: Irwin MacGraw-Hill, 2000. 